\title{
Tingkat Kepuasan Kerja Dilihat Dari Perspektif Lingkungan Kerja Sosial dan Pengembangan Karir
}

\author{
A. Nurdini ${ }^{1}$, S. Sumiyati \& R. Purnama \\ Universitas Pendidikan Indonesia \\ atinnurdini@student.upi.edu
}

\begin{abstract}
The purpose of this study was to find out the influence of social work environment on job satisfaction, the influence of career development on job satisfaction, and the influence of social work environment and career development on job satisfaction. Object of analysis in this research is employees of government service. This type of research is using verificative with explanatory survey method of 106 respondents. This study indicates that the influence of the social work environment to job satisfaction are included in the low category. Career development included in medium category to job satisfaction. The influence of social work environment and career development on job satisfaction is medium category. The results of the present study suggest if social work environment in conducive conditions, then it will increase job satisfaction. The implementation of career development is good, then job satisfaction will increase. In addition if social work environmental conditions are conducive and implementation of career development is good, then the job satisfaction will increase.
\end{abstract}

Keyword: Career Development; Job Satisfaction; Social Work Environment

Abstrak: Tujuan penelitian ini adalah mengetahui pengaruh lingkungan kerja sosial terhadap kepuasan kerja, pengaruh pengembangan karir terhadap kepuasan kerja, serta pengaruh lingkungan kerja sosial dan pengembangan karir terhadap kepuasan kerja. Objek yang menjadi unit analisis dalam penelitian ini adalah pegawai dinas pemerintahan. Jenis penelitian yang digunakan adalah verifikatif dengan metode yang digunakan adalah explanatory survey dengan jumlah sampel 106 responden. Hasil penelitian ini menemukan bahwa pengaruh lingkungan kerja sosial terhadap kepuasan kerja termasuk ke dalam kategori rendah. Pengembangan karir berpengaruh sedang terhadap kepuasan kerja. Lingkungan kerja sosial dan pengembangan karir berpengaruh sedang terhadap kepuasan kerja. Dalam penelitian ini ditemukan jika kondisi lingkungan kerja sosial kondusif, maka akan meningkatkan kepuasan kerja. Implementasi pengembangan karir baik, maka kepuasan kerja pegawai akan meningkat. Selain itu jika kondisi lingkungan kerja sosial kondusif dan implementasi pengembangan karir baik, maka kepuasan kerja pegawai akan meningkat.

Kata Kunci: Kepuasan Kerja; Lingkungan Kerja Sosial; Pengembangan Karir

\section{PENDAHULUAN}

Kualitas sumber daya manusia dapat menentukan kemajuan suatu organisasi, sehingga sangatlah penting bagi suatu organisasi untuk memperhatikan kualitas sumber daya manusia (Senen \& Solihat, 2008) yang mampu mempengaruhi produktivitas dalam suatu organisasi (George \& K.A, 2015). Produktivitas dalam organisasi ditentukan oleh kepuasan kerja dan kinerja pegawai (Valaei \& Jiroudi, 2016), bila tingkat produktivitasnya tinggi maka organisasi dinyatakan berhasil namun jika lebih rendah dari standar penurunan maka dikatakan kurang sukses (Masharyono, Sumiyati, \& Toyib, 2016). Peningkatan terhadap penelitian tentang manajemen sumber daya manusia, menunjukkan minat peneliti terus meninggi berdasarkan hasil dari kepuasan kerja tingkat kelompok, yang berperan dalam mempengaruhi dampak kebijakan organisasi dan praktek pada kinerja organisasi (Cambre, Kippers, Veldhoven, \& Witte, 2014).

Tujuan organisasi merupakan hal penting yang perlu dicapai (Senen \& Widyanata, 2016) 
tanpa adanya sumber daya manusia yang berkualitas dalam organisasi, tidak mungkin organisasi tersebut dapat mencapai tujuan yang diinginkan (Masharyono, 2015) dan kepuasan kerja pegawai dapat menentukan kegagalan atau keberhasilan organisasi tersebut dalam mencapai tujuan serta memiliki komitmen untuk perbaikan kualitas secara terus-menerus (Menezes, 2012). Pegawai dengan kepuasan kerja merupakan keuntungan bagi organisasi, karena pegawai yang memiliki kepuasan kerja tinggi maka akan memiliki nilai absensi yang rendah dan memiliki masa bekerja yang lebih lama, kemudian cenderung akan bekerja lebih keras serta menunjukan prestasi yang lebih baik (Dessler, 2013: 58).

Sejalan dengan hasil penelitian dari Alonderiene \& Majauskaite (2016) menyatakan bahwa pegawai yang merasa puas terhadap pekerjaannya tidak akan berpikir untuk meninggalkan organisasi. Berbeda dengan pegawai yang kurang puas, mereka akan meninggalkan organisasi dengan mudah. Permasalahan kepuasan kerja menjadi masalah yang dapat dijumpai di berbagai organisasi dan perusahaan baik itu jasa maupun manufaktur. Hasil penelitian yang dilakukan oleh Edduar Hendri (2012) menyatakan bahwa kepuasan kerja yang rendah terjadi pada salah satu jasa asuransi di Palembang, bahwa tidak puasnya seorang pegawai dikarenakan oleh kurang kondusifnya lingkungan kerja fisik dan non fisik terhadap pegawai menyebabkan banyak pegawai yang keluar dari perusahaan jasa tersebut.

Kepuasan kerja menunjukkan hubungan yang negatif terhadap keterlambatan, ketidakhadiran, niat untuk keluar (Bednarska \& Szczyt, 2015). Organisasi yang baik senantiasa memperhatikan dan memantau tingkat kepuasan kerja pegawainya, karena hal tersebut mempengaruhi tingkat absensi, keterlambatan, perputaran kerja, semangat kerja, keluhan-keluhan dan masalah SDM vital lainya. Semakin tinggi tingkat kepuasan kerja pegawai akan menumbuhkan keinginan untuk berkontribusi penuh pada kemajuan organisasi dengan bertanggung jawab atas kewajibannya sebagai pegawai di organisasi (Bhatti \& Khoso, 2013). Dampak tersebut juga menunjukkan bahwa terjadinya penurunan kepuasan kerja sesuai dengan pendapat As'ad (2010: 17) yang menjelaskan bahwa yang dapat dijadikan indikasi menurunnya kepuasan kerja adalah tingginya tingkat absensi (absenteeism) dan tingginya turnover. Berikut Tabel 1 yang menunjukkan ketidakhadiran pegawai dinas pemerintahan tahun 2015-2017.

Tabel 1. Ketidakhadiran Pegawai Tahun 2015-2017

\begin{tabular}{cccccc}
\hline \multirow{2}{*}{ Tahun } & \multicolumn{3}{c}{ Keterangan } & & \\
\cline { 2 - 4 } & Sakit & Izin & $\begin{array}{c}\text { Tanpa } \\
\text { Keterangan }\end{array}$ & Total & Persentase \\
\hline 2015 & 76 & 134 & 137 & 347 & $3.9 \%$ \\
2016 & 140 & 152 & 182 & 474 & $12.2 \%$ \\
2017 & 239 & 207 & 225 & 671 & $17.3 \%$ \\
\hline
\end{tabular}

Sumber: Data Internal Organisasi 2017

Tabel 1 menunjukkan bahwa setiap tahunnya persentase ketidakhadiran terus meningkat. Jumlah ketidakhadiran terbagi dalam tiga kategori yaitu sakit, izin dan tanpa keterangan. Ketidakhadiran pegawai pada tahun 2017 mencapai $17.3 \%$. Kategori tanpa keterangan tiap tahunnya selalu memiliki jumlah ketidakhadiran yang paling tinggi dibandingkan dengan kategori lainnya. Kategori kedua dengan jumlah ketidakhadiran tertinggi yaitu kategori izin dan yang terakhir adalah kategori sakit dengan jumlah ketidakhadiran di posisi terakhir. Dampak rendahnya kepuasan kerja akan sangat merugikan perusahaan, teori tersebut dapat didukung dengan hasil penelitian Verhaest \& Verhofstadt (2016) bahwa dampak dari kepuasan kerja yang renda yaitu penurunan kinerja karyawan dan ketidakinginan karyawan untuk berada dalam lingkungan organisasi, hal tersebut dapat merugikan organisasi terutama dalam produktivitas kerja dan ketidaksesuaian antara output yang dihasilkan dengan apa yang sudah ditetapkan oleh organisasi.

Teori yang digunakan untuk mengatasi permasalahan organisasi yaitu pendekatan manajemen sumber daya manusia (Rivai, 2011). As'ad (2010: 114) menyatakan faktor-faktor yang memberikan kepuasan kerja diantaranya: 1) Faktor individual, meliputi umur, kesehatan, watak dan harapan. 2) Faktor sosial, meliputi hubungan kekeluargaan, pandangan masyarakat, kesempatan berkerasi, kegiatan perserikatan pekerja, kebebasan berpolitik dan hubungan kemasyarakatan. 3) Faktor utama dalam pekerjaan, meliputi upah, pengawasan, ketentraman kerja, kondisi kerja dan kesempatan untuk maju. Tingginya tingkat kepuasan kerja terdiri dari faktor-faktor seperti peluang motivasi, alur kerja 
dan karir, lingkungan kerja fisik yang dirasakan dan pengalaman di lingkungan kerja memainkan peran penting untuk kepuasan kerja dan kinerja individu (Rothe, Lindholm, Hyvonen, \& Nenonen, 2012).

MIT Sloan Management Review melakukan survei karyawan berskala besar di negara bagian selatan Amerika Serikat dan menemukan bahwa dukungan rekan kerja dapat mengurangi stres kerja akibat terjadinya perlakuan buruk oleh pelanggan, pengawas, dan rekan kerja lainnya (https://sloanreview.mit.edu/). Organisasi harus dapat memperhatikan kondisi yang ada baik didalam maupun diluar ruangan tempat kerja, sehingga pegawai dapat bekerja dengan lancar dan merasa aman. Kedua, menurunnya kepuasan kerja dapat didasarkan pada kurangnya perhatian untuk melakukan pengembangan karir. Penting untuk mengelola pengembangan karir pada seluruh pegawai sehingga berpengaruh positif pada kepuasan kerja pegawai (Altaf, Yousaf, Tahir, \& Bagram, 2013).

Berdasarkan latar belakang masalah diatas, maka penulis merumuskan beberapa rumusan penelitian yaitu bagaimana pengaruh lingkungan kerja sosial terhadap kepuasan kerja pegawai di dinas pemerintahan, bagaimana pengaruh pengembangan karir terhadap kepuasan kerja pegawai di dinas pemerintahan, dan pengaruh lingkungan kerja sosial dan pengembangan karir terhadap kepuasan kerja pegawai di dinas pemerintahan. Tujuan dari penelitian ini adalah untuk mengetahui pengaruh lingkungan kerja sosial terhadap kepuasan kerja pegawai di dinas pemerintahan, pengaruh pengembangan karir terhadap kepuasan kerja pegawai di dinas pemerintahan, dan pengaruh lingkungan kerja sosial dan pengembangan karir terhadap kepuasan kerja pegawai di dinas pemerintahan.

Manajemen sumber daya manusia (SDM) adalah peranan kerja individu untuk mencapai tujuan organisasi (Mondy \& Martocchio, 2016). Salah satu faktor penentu keberhasilan perusahaan dalam mencapai tujuannya adalah kualitas sumber daya manusia, karena sumber daya manusia memiliki peranan sebagai pengelola sistem yang perlu dipertahankan keberadaannya di organisasi dengan memperhatikan tingkat kepuasan kerja pegawai tersebut (Rivai \& Sagala, 2009).

Kepuasan kerja dapat didefinisikan sebagai sikap dan perasaan orang tentang pekerjaan mereka. Kepuasan kerja ditunjukkan dengan sikap positif yang menguntungkan terhadap pekerjaanm dan sikap negatif yang tidak menguntungkan terhadap pekerjaan menunjukkan ketidakpuasan kerja (Armstrong, 2014). Kepuasan karyawan dianggap sebagai keadaan emosional tentang keseluruhan perasaan mengenai pekerjaan (Chen, Sparrow, \& Cooper, 2016).

Faktor-faktor yang mempengaruhi kepuasan kerja, yaitu (Robbins \& Judge, 2013), 1) Pekerjaan yang secara mentalitas memberi tantangan, 2) Penghargaan yang layak, 3) Kondisi kerja yang menunjang, 4) Rekan kerja yang mendukung. Usman (2011: 497) mengatakan bahwa faktorfaktor yang mempengaruhi kepuasan kerja yaitu 1) imbalan jasa, 2) rasa aman, 3) pengaruh antar pribadi, 4) kondisi lingkungan kerja, 5) kesempatan untuk pengembangan, dan 6) peningkatan diri.

Dimensi-dimensi kepuasan kerja, yaitu (Luthan, 2015): 1) The work itself, kepuasan pekerjaan itu sendiri merupakan sumber utama kepuasan, dimana pekerjaan tersebut memberikan tugas yang menarik, kesempatan untuk belajar, kesempatan untuk menerima tanggung jawab dan kemajuan untuk karyawan. 2) Pay, gaji sebagai faktor multidimensi dalam kepuasan kerja merupakan sejumlah upah/ uang yang diterima dan tingkat dimana hal ini bisa dipandang sebagai hal yang dianggap pantas dibandingkan dengan orang lain dalam organisasi. 3) Promotion, kesempatan promosi adalah kesempatan untuk maju dalam organisasi, sepertinya memiliki pengaruh yang berbeda pada kepuasan kerja. 4) Supervision, pengawasan merupakan kemampuan penyelia untuk memberikan bantuan teknis dan dukungan perilaku. 5) Coworkers, pada umumnya, rekan kerja yang kooperatif merupakan sumber kepuasan kerja yang paling sederhana pada karyawan secara individu

Menurut Dewi Hanggraeni (2012), penilaian kinerja dimanfaatkan oleh manajemen untuk membantu pengambilan keputusan yang bersangkutan dengan karyawan seperti: promosi, transfer dan pemberhentian, mengidentifikasi kebutuhan pelatihan dan pengembangan karyawan dan untuk menyediakan kriteria seleksi serta evaluasi program pelatihan karyawan, menyediakan umpan balik bagi karyawan mengenai bagaimana atasan mereka menilai kinerja mereka dan menyediakan suatu dasar bagi distribusi penghargaan. 
Henry Simamora (Askolani, 2010: 60) berpendapat lain yang mengungkapkan bahwa pengembangan karir (career development) adalah pendekatan formal yang diambil organisasi untuk memastikan bahwa orang-orang dengan kualifikasi dan pengalaman yang tepat tersedia pada saat yang dibutuhkan. Gary Dessler (2009: 5) "Pengembangan karir adalah serangkaian aktivitas sepanjang hidup (seperti workshop) yang berkontribusi pada eksplorasi, pemantapan keberhasilan, dan pencapaian karir seseorang". Veithzal Rivai dan Ella Jauvani Sagala dan Ella Jauvani Sagala (2013: 274) "Pengembangan karir adalah proses peningkatan kemampuan kerja individu dalam rangka mencapai karir yang diinginkan".

Terdapat beberapa hal yang harus karyawan pahami dengan mengetahui faktor-faktor yang dapat mempengaruhi pengembangan karir karyawan menurut Sondang P. Siagian (2013: 215) yaitu, 1) Prestasi kerja, tanpa prestasi kerja yang memuaskan, sukar bagi seorang pekerja untuk diusulkan oleh atasannya agar dipertimbangkan untuk dipromosikan ke pekerjaan atau jabatan yang tinggi di masa depan, 2) Kesetiaan pada organisasi, dedikasi seorang karyawan yang ingin terus berkarya dalam organisasi tempatnya bekerja untuk jangka waktu lama, 3) Mentor dan sponsor, mentor adalah orang yang memberikan nasihatnasihat atau saran-saran kepada karyawan dalam upaya mengembangkan karirnya, sementara sponsor adalah seseorang di dalam perusahaan yang dapat menciptakan kesempatan bagi karyawan untuk mengembangkan karirnya, 4) Dukungan para bawahan, dukungan yang diberikan para bawahan dalam bentuk mensukseskan tugas manajer yang bersangkutan, 5) Kesempatan untuk bertumbuh, kesempatan yang diberikan kepada karyawan untuk meningkatkan kemampuannya, baik melalui pelatihan-pelatihan, kursus dan juga melanjutkan jenjang pendidikannya. Dimensi pengembangan karir menurut Gary Dessler (2009: 5)yaitu terdiri dari: 1) Tanggung jawab karir, 2) Keahlian, 3) Informasi karir, 4) Perencanaan karir, 5) Kesempatan pengembangan.

Lingkungan kerja sosial dapat pula disebut sebagai lingkungan kerja non fisik ataupun lingkungan psikis. Lingkungan kerja non fisik adalah semua keadaan yang terjadi yang berkaitan dengan hubungan kerja, baik hubungan dengan atasan maupun hubungan sesama rekan kerja, ataupun hubungan dengan bawahan (Sedarmayanti, 2011: 26). Pendapat selanjutnya menurut Duane P. Schultz dan Sydney E. Schultz yang diterjemahkan oleh A.P Mangkunegara (2011:105) mengungkapkan bahwa lingkungan kerja sosial adalah semua aspek fisik psikologis kerja dan peraturan kerja yang dapat mempengaruhi kepuasan kerja dan pencapaian produktivitas. Sedarmayanti (2011:28) mengemukakan yang dapat mempengaruhi terbentuknya suatu kondisi lingkungan kerja terkait dengan, 1) hubungan dengan atasan, 2) hubungan dengan rekan kerja.

\section{METODE PENELITIAN}

Metode yang digunakan dalam penelitian ini adalah metode survey atau explanatory survey. Metode ini bertujuan untuk mengetahui pengaruh antar variabel dengan cara pengujian hipotesis. Data yang digunakan adalah data sekunder yang terdiri dari data rekapitulasi ketidakhadiran, dan pra penelitian.

Sampel dalam penelitian ini adalah seluruh pegawai dinas pemerintahan, penarikan sampel dengan menggunakan metode sampel jenuh, yaitu metode yang mengambil seluruh jumlah populasi. Teknik pengumpulan data yang dilakukan dalam penelitian ini melalui penyebaran kuesioner dan wawancara. Teknik analisis data yang digunakan dalam penelitian ini adalah analisis verifikatif. Analisis verifikatif digunakan untuk untuk melihat pengaruh lingkungan kerja sosial dan pengembangan karir terhadap kepuasan kerja (Sugiyono, 2017: 147).

Variabel dalam penelitian terdiri dari lingkungan kerja sosial, pengembangan karir dan kepuasan kerja. Penelitian ini menggunakan pengukuran data berskala interval. Skala berusaha mengukur arti suatu objek atau konsep bagi responden. Skala yang digunakan dalam penelitian ini adalah skala Semantic Differential.

\section{HASIL DAN PEMBAHASAN}

Penelitian ini yang terdiri dari variabel bebas yaitu lingkungan kerja sosial $\left(\mathrm{X}_{1}\right)$ dan pengembangan karir $\left(\mathrm{X}_{2}\right)$, sedangkan untuk variabel terikatnya adalah kepuasan kerja (Y). Untuk mengetahui pengaruh lingkungan kerja sosial terhadap 
kepuasan kerja, pengaruh pengembangan karir terhadap kepuasan kerja, dan pengaruh lingkungan kerja sosial dan pengembangan karir terhadap kepuasan kerja dilakukan pengujian regresi linier berganda.

Model persamaan regresi berganda yang akan dibentuk pada penelitian ini sebagai berikut:

$$
\mathbf{Y}=\mathbf{a}+\mathbf{b}_{1} \mathbf{X}_{1}+\mathbf{b}_{2} \mathbf{X}_{2}+\mathrm{e}
$$

Sumber: Sugiyono (2017: 192)

Dimana:

Y = Variabel terikat (kepuasan kerja)

a $\quad=$ Konstanta

$\mathrm{b}_{1} \mathrm{~b}_{2}=$ Koefisien regresi

$\mathrm{X}_{1}=$ Variabel bebas (lingkungan kerja sosial)

$\mathrm{X}_{2}=$ Variabel bebas (pengembangan karir)

$\mathrm{e} \quad=$ Kesalahan pengganggu (standard eror)

Berdasarkan hasil pengolahan data dengan

bantuan program SPSS 24.0 for windows, diperoleh koefisien regresi linear berganda sebagai berikut.

Tabel 2. Koefisien korelasi model summary

Coefficients $^{\mathrm{a}}$

\begin{tabular}{|c|c|c|c|c|}
\hline \multirow[b]{2}{*}{ Model } & \multicolumn{2}{|c|}{$\begin{array}{l}\text { Unstandardized } \\
\text { Coefficients }\end{array}$} & $\begin{array}{l}\text { Standardized } \\
\text { Coefficients }\end{array}$ & \multirow[b]{2}{*}{ Sig. } \\
\hline & $\mathrm{B}$ & Std. Error & rBeta & \\
\hline $\begin{array}{ll}1 & (\text { Constant })\end{array}$ & 19,858 & 8,546 & & $2,324,022$ \\
\hline $\begin{array}{l}\text { Lingkungan } \\
\text { Kerja Sosial }\end{array}$ & ,406 & ,132 & ,269 & 3,083,003 \\
\hline $\begin{array}{l}\text { Pengembangan } \\
\text { Karir }\end{array}$ & ,641 &, 113 & ,496 & $5,685,000$ \\
\hline
\end{tabular}

a. Dependent Variable: Kepuasan Kerja

Sumber: Hasil Pengolahan Data, 2018

Berasarkan Tabel 2 pada kolom B, tercantum nilai konstanta dan nilai koefisien regresi linear berganda untuk variabel bebas. Berdasarkan nilainilai itu maka dapat ditentukan model regresi linear berganda yang dinyatakan dalam bentuk persamaan sebagai berikut:

$$
\begin{gathered}
\mathbf{Y}=\mathbf{a}+\mathbf{b}_{1} \mathbf{X}_{1}+\mathbf{b}_{2} \mathbf{X}_{\mathbf{2}}+\mathbf{e} \\
\mathrm{Y}=19,858+0,406 \mathrm{X}_{1}+0,641 \mathrm{X}_{2}
\end{gathered}
$$

Berdasarkan persamaan regresi linier berganda di atas, menunjukkan bahwa koefisien regresi lingkungan kerja sosial $\left(b_{1}\right)$ bernilai positif. Hal ini menunjukkan adanya arah hubungan dari persamaan positif yang menggambarkan adanya hubungan positif, artinya lingkungan kerja sosial mempunyai hubungan searah dengan kepuasan kerja. Dapat dikatakan jika lingkungan kerja sosial mengalami kenaikan, maka nilai kepuasan kerja akan meningkat, begitu pun sebaliknya, jika lingkungan kerja sosial mengalami penurunan, maka nilai kepuasan kerja akan menurun.
Koefisien regresi pada variabel pengembangan karir $\left(b_{2}\right)$ bernilai positif. Hal ini menunjukkan adanya arah hubungan dari persamaan positif yang menggambarkan adanya hubungan positif, artinya pengembangan karir mempunyai hubungan searah dengan kepuasan kerja. Dapat dikatakan jika pengembangan karir mengalami kenaikan, maka nilai kepuasan kerja akan meningkat, begitu pun sebaliknya, jika pengembangan karir mengalami penurunan, maka nilai kepuasan kerja akan menurun.

Untuk mengetahui besarnya persentase pengaruh $\mathrm{X}_{1}$ dan $\mathrm{X}_{2}$ terhadap $\mathrm{Y}$, koefisien determinasi dapat diketahui dengan rumus yang dikemukakan Riduwan (2013: 136) yaitu :

$$
\mathrm{KD}=\mathrm{r}^{2} \times 100 \%
$$

Keterangan :

$$
\begin{array}{ll}
\mathrm{KD} & =\text { Koefisien determinasi } \\
\mathrm{r} & =\text { Koefisien korelasi } \\
100 \% & =\text { Konstanta }
\end{array}
$$

\begin{tabular}{|c|c|c|c|c|}
\hline \multicolumn{5}{|c|}{ Model Summary } \\
\hline Model & $\mathrm{R}$ & R Square & $\begin{array}{l}\text { Adjusted } \\
\text { R Square }\end{array}$ & $\begin{array}{l}\text { Std. Error of } \\
\text { the Estimate }\end{array}$ \\
\hline 1 &, $551^{\mathrm{a}}$ & ,303 & ,296 & 13,26617 \\
\hline
\end{tabular}

Pengaruh lingkungan kerja terhadap kepuasan kerja dapat dilihat dari hasil Tabel 3 berikut:

Tabel 3. Koefisien Determinasi Secara Parsial

Sumber: Hasil Pengolahan Data, 2018

$$
\begin{aligned}
\mathrm{KD} & =\mathrm{r}^{2} \times 100 \% \\
& =(0,551)^{2} \times 100 \% \\
& =30,4 \%
\end{aligned}
$$

Angka koefisien korelasi (R) sebesar 0,551. Hal ini berarti hubungan antara lingkungan kerja sosial dengan kepuasan kerja sebesar 0,551. Dari angka tersebut jika diinterpretasikan dapat diambil kesimpulan bahwa hubungan antara lingkungan kerja sosial dengan kepuasan kerja adalah rendah.

Maka diperoleh nilai KD sebesar 30,4\% yang menunjukkan arti bahwa lingkungan kerja sosial memberikan pengaruh sebesar $30,4 \%$ terhadap kepuasan kerja. Sedangkan sisanya sebesar 69,6\% dipengaruhi oleh faktor yang tidak diteliti pada penelitian ini.

Pengaruh pengembangan karir terhadap kepuasan kerja dapat dilihat dari hasil Tabel 4 berikut:

Tabel 4. Koefisien Determinasi Secara Parsial Model Summary 


\begin{tabular}{lrrrr}
\hline Model & R & R Square & $\begin{array}{c}\text { Adjusted } \\
\text { R Square }\end{array}$ & $\begin{array}{l}\text { Std. Error of } \\
\text { the Estimate }\end{array}$ \\
\hline 1 &, $649^{\mathrm{a}}$ &, 421 &, 415 & 12,09650 \\
\hline
\end{tabular}

a. Predictors: (Constant), Pengembangan Karir

b. Dependent Variable: Kepuasan Kerja

Sumber: Hasil Pengolahan Data, 2018

$\mathrm{KD}=\mathrm{r}^{2} \times 100 \%$

$=(0,649)^{2} \times 100 \%$

$=42,1 \%$

Angka koefisien korelasi (R) sebesar 0,649.

Hal ini berarti hubungan antara pengembangan karir dengan kepuasan kerja sebesar 0,649. Dari angka tersebut jika diinterpretasikan dapat diambil kesimpulan bahwa hubungan antara pengembangan karir dengan kepuasan kerja adalah sedang. Maka diperoleh nilai $\mathrm{KD}$ sebesar $42,1 \%$ yang menunjukkan arti bahwa pengembangan karir memberikan pengaruh sebesar 42,1\% terhadap kepuasan kerja. Sedangkan sisanya sebesar 57,9\% dipengaruhi oleh faktor yang tidak diteliti pada penelitian ini.

Pengaruh lingkungan kerja sosial dan pengembangan karir terhadap kepuasan kerja dapat dilihat dari hasil Tabel 5 berikut:

Tabel 5. Koefisien Determinasi Secara Simultan

\begin{tabular}{|c|c|c|c|c|}
\hline \multicolumn{5}{|c|}{ Model Summary } \\
\hline Model & $\mathrm{R}$ & R Square & $\begin{array}{l}\text { Adjusted } \\
\text { R Square }\end{array}$ & $\begin{array}{l}\text { Std. Error of } \\
\text { the Estimate }\end{array}$ \\
\hline 1 &, $685^{\mathrm{a}}$ &, 470 & ,459 & 11,63015 \\
\hline
\end{tabular}

a. Predictors: (Constant), Pengembangan Karir,

Lingkungan Kerja Sosial

b. Dependent Variable: Kepuasan Kerja

Sumber: Hasil Pengolahan Data, 2018

$\mathrm{KD}=\mathrm{r}^{2} \times 100 \%$

$=(0,685)^{2} \times 100 \%$

$=46,9 \%$

Angka koefisien korelasi (R) sebesar 0,685. Hal ini berarti hubungan antara lingkungan kerja sosial dan pengembangan karir dengan kepuasan kerja sebesar 0,685. Dari angka tersebut jika diinterpretasikan dapat diambil kesimpulan bahwa hubungan antara lingkungan kerja sosial dan pengembangan karir dengan kepuasan kerja adalah sedang.

Maka diperoleh nilai KD sebesar 46,9\% yang menunjukkan arti bahwa lingkungan kerja sosial dan pengembangan karir memberikan pengaruh sebesar 46,9\% terhadap kepuasan kerja. Sedangkan sisanya sebesar 53,1\% dipengaruhi oleh faktor yang tidak diteliti pada penelitian ini.

Uji statistik $\mathrm{t}$ pada dasarnya menunjukkan seberapa jauh pengaruh satu variabel penjelas/independen secara individual dalam menerangkan variabel dependen. Untuk mengetahui besarnya persentase pengaruh lingkungan kerja sosial dan pengembangan karir terhadap kepuasan kerja. Maka menggunakan program SPSS 22.0 for windows, diperoleh output sebagai berikut:

Tabel 6. Nilai Signifikan Uji t

\begin{tabular}{|c|c|c|c|c|c|}
\hline \multicolumn{6}{|c|}{ Coefficients $^{\mathrm{a}}$} \\
\hline \multirow[b]{2}{*}{ Model } & $\begin{array}{r}\text { Unstan } \\
\text { Coeff } \\
\end{array}$ & $\begin{array}{l}\text { ardized } \\
\text { cients }\end{array}$ & $\begin{array}{l}\text { Standardized } \\
\text { Coefficients }\end{array}$ & \multirow[b]{2}{*}{$\mathrm{t}$} & \multirow[b]{2}{*}{ Sig. } \\
\hline & $\mathrm{B}$ & $\begin{array}{l}\text { Std. } \\
\text { Error }\end{array}$ & Beta & & \\
\hline (Constant) & 51,554 & 7,388 & & 6,978 & 000 \\
\hline Lingkungan & ,832 & 124 & ,551 & 6,726 & ,000 \\
\hline $\begin{array}{l}\text { Kerja Sosial } \\
\text { (Constant) }\end{array}$ & 26,272 & 8,621 & & 3,047 & ,003 \\
\hline $\begin{array}{l}\text { Pengembangan } \\
\text { Karir }\end{array}$ & 838 & ,096 & 649 & 8,689 & ,000 \\
\hline
\end{tabular}

a. Dependent Variable: Kepuasan Kerja

Sumber: Hasil Pengolahan Data, 2018

Berdasarkan Tabel 6 perolehan $t_{\text {hitung }}$ sebesar 6,726 untuk lingkungan kerja sosial dan 8,689 untuk pengembangan karir. Tingkat signifikan $(\alpha)$ sebesar 5\%, dan derajat kebebasan df $=\mathrm{n}-\mathrm{k}=106$ $-3=103$ didapat nilai $t_{\text {tabel }}$ 1,660. Dikarenakan $t_{\text {hitung }}>t_{\text {tabel }}$ atau 6,726>1,660 maka $\mathrm{H}_{\mathrm{a}}$ diterima artinya lingkungan kerja sosial berpengaruh signifikan terhadap kepuasan kerja.

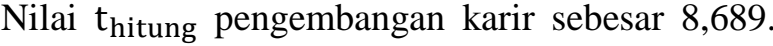
Dikarenakan $t_{\text {hitung }}>t_{\text {tabel }}$ atau 8,689>1,660 maka $\mathrm{H}_{\mathrm{a}}$ diterima, artinya pengembangan karir berpengaruh signifikan terhadap kepuasan kerja, dengan besarnya pengaruh pengembangan karir terhadap kepuasan kerja.

Uji statistik $F$ pada dasarnya menunjukkan apakah semua varibel independen atau bebas yang dimasukkan dalam model mempunyai pengaruh secara bersama-sama terhadap variabel dependen/terikat. Uji ini digunakan untuk menguji siginifikansi pengaruh lingkungan kerja sosial dan pengembangan karir terhadap kepuasan kerja rumus uji F atau uji ANOVA dijelaskan pada tabel berikut.

Tabel 7. Nilai Signifikan Uji F

\begin{tabular}{|c|c|c|c|c|}
\hline Model & $\begin{array}{l}\text { Sum of } \\
\text { Squares df }\end{array}$ & $\begin{array}{l}\text { Mean } \\
\text { Square }\end{array}$ & $\mathrm{F}$ & Sig. \\
\hline $1 \quad$ Regression & 12332,6372 & 6166,318 & 45,588 &, $000^{\mathrm{b}}$ \\
\hline Residual & $13931,826 \quad 103$ & 135,260 & & \\
\hline
\end{tabular}


Total 26264,462 105

a. Dependent Variable: Kepuasan Kerja

b. Predictors: (Constant), Pengembangan Karir, Lingkungan Kerja Sosial

Sumber: Hasil Pengolahan Data, 2018

Berdasarkan tabel 4.33 menjelasakan perolehan $\mathrm{F}_{\text {hitung }}$ sebesar 45,588 untuk dengan $\mathrm{p}$ value (sig) 0,000. Dengan $\alpha=0,05$, dan derajat

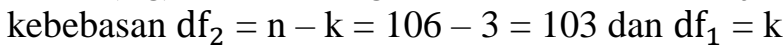
- $1=3-1=2$, maka didapat $F_{\text {tabel }} 3,08$. Dikarenakan $\mathrm{F}_{\text {hitung }}>\mathrm{F}_{\text {tabel }}(45,588>3,08)$, maka $\mathrm{H}_{0}$ ditolak dan $\mathrm{H}_{\mathrm{a}}$ diterima, artinya lingkungan kerja sosial dan pengembangan karir secara bersama-sama berpengaruh signifikan terhadap kepuasan kerja.

\section{KESIMPULAN DAN SARAN}

Hasil penelitian menyatakan bahwa, lingkungan kerja sosial mempunyai pengaruh terhadap kepuasan kerja dengan kategori rendah. Hal ini menunjukkan bahwa semakin kondusif lingkungan kerja sosial organisasi, maka semakin tinggi pula produktivitas pegawai dinas pemerintahan. Pengembangan karir berpengaruh terhadap kepuasan kerja dengan kategori sedang, hal tersebut menunjukkan bahwa semakin tinggi pengembangan karir, maka akan semakin tinggi pula kepuasan kerja pegawai di dinas pemerintahan. Hasil lainnya adalah lingkungan kerja sosial dan pengembangan karir berpengaruh terhadap kepuasan kerja pegawai dengan kategori sedang. Hal tersebut menjelaskan bahwa semakin kondusif lingkungan kerja sosial dan semakin baik pengembangan karir, maka akan semakin tinggi kepuasan kerja pegawai di dinas pemerintahan.

Berdasarkan hasil penelitian, maka penulis menyarankan beberapa hal yang dapat meningkatkan kepuasan kerja pegawai melalui lingkungan kerja sosial. Organisasi harus memberikan dorongan dan menciptakan suasana yang nyaman agar dapat menjaga hubungan baik antara atasan dengan bawahan dan dengan sesama rekan kerja. Sedangkan untuk meningkatkan kepuasan kerja pegawai melalui pengembangan karir dapat dilakukan dengan cara perusahaan memberikan promosi dan rotasi yang sesuai untuk pegawai demi kemajuan dan tercapainya tujuan organisasi.

\section{DAFTAR PUSTAKA}

Alonderiene, R., \& Majauskaite, M. (2016). Leadership Style And Job Satisfaction In Higher Education Institutions. International Journal of Educational Management, Vol. 30(Iss 1), pp. 140-164. https://doi.org/10.1108/IJEM-08-2014-0106

Altaf, M., Yousaf, U., Tahir, M., \& Bagram, M. M. M. (2013). Job Satisfaction And Employees Participation In Government Sector Organization Of Pakistan. Asian Journal of Management Research, Vol. 3(Iss. 2), pp. 384-393.

Armstrong, M. (2014). Armstrong's Handbook Of Human Resource Management Practice (13th Editi). London: Kogan Page.

As'ad, M. (2010). Pengukuran Kepuasan Kerja Karyawan. Yogyakarta: Liberty.

Askolani. (2010). Manajemen Sumber Daya Manusia. Bandung: UPI PRESS.

Bednarska, M. A., \& Szczyt, M. (2015). Variations In Job Satisfaction In Service Industries: Comparative International Analysis. Foresight, Vol. 17(Iss 6), pp. 599-615. https://doi.org/10.1108/FS-08-2013-0037

Bhatti, A. G., \& Khoso, A. A. (2013). Job Satisfaction Among Government \& NonGovernment Employees Of Hyderabad City. Ma'arif Research Journal, Vol. 3(No. 7), pp. 21-34.

Cambre, B., Kippers, E., Veldhoven, M. van, \& Witte, H. De. (2014). Jobs And Organisations: Explaining Group Level Differences In Job Satisfaction In The Banking Sector. Personnel Review, Vol. 41(No. 2), pp. 200-215. https://doi.org/10.1108/00483481211200033

Chen, P., Sparrow, P., \& Cooper, C. (2016). The Relationship Between Person-Organization Fit And Job Satisfaction. Journal of Managerial Psychology, Vol. 31(Iss 5), pp. 946-959. https://doi.org/10.1108/JMP-082014-0236

Dessler, G. (2009). Manajemen Sumber Daya Manusia. Jakarta: Salemba Empat.

Dessler, G. (2013). Human Resource Management. New York: Pearson Education, Inc.

Dewi Hanggraeni. (2012). Pengaruh Kepuasan Kerja Terhadap Kinerja Karyawan.

George, E., \& K.A, Z. (2015). Job Related Stress And Job Satisfaction: A Comparative Study Among Bank Employees. Journal of 
Management Development, Vol. 34(Iss 3), pp. 316-329. https://doi.org/10.1108/JMD-072013-0097

Hendri, E. (2012). Pengaruh Lingkungan Kerja Fisik Dan Non Fisik Terhadap Kepuasan Kerja Karyawan Pada PT. Asuransi Wahana Tata Cabang Palembang. Jurnal Media Wahana Ekonomika, Vol. 9(No.3), 1-16.

Luthan, F. (2006). Perilaku organisasi. Yogyakarta: Penerbit Andi.

Mangkunegara, A. A. P. (2011). Manajemen Sumber Daya Manusia. Bandung: PT. Remaja Rosdakarya.

Masharyono. (2015). Pengaruh Job Characteristics terhadap Semangat Kerja Pegawai (Survey pada Pegawai PNS di Lingkungan Disparbud Jabar). Jurnal Riset Akuntansi Dan Keuangan, Vol. 3(No. 3), pp. 813-830.

Masharyono, Sumiyati, \& Toyib. (2016). Physical Work Environment Effect on Employee Productivity of Textile Industry. Business and Management Research, Vol. 15, pp. 630 632.

Menezes, L. M. de. (2012). Job Satisfaction And Quality Management: An Empirical Analysis. International Journal of Operations \& Production Management, Vol. 32(Iss 3), pp. 308-328. https://doi.org/10.1108/01443571211212592

Mondy, R. W., \& Martocchio, J. J. (2016). Human Resource Management (Fourteenth). Edinburgh Gate: Pearson Education, Inc.

Riduwan. (2013). Skala Pengukuran VariabelVariabel Penelitian. Bandung: Alfabeta.

Rivai, V. (2011). Manajemen Sumber Daya Manusia Untuk Perusahaan Dari Teori Ke Praktek. Jakarta: PT. Rajagrafindo Persada.

Rivai, V., \& Sagala, E. J. (2009). Manajemen Sumber Daya Manusia Untuk Perusahaan. Jakarta: PT. Rajagrafindo Persada.

Robbins, S. P., \& Judge, T. A. (2013). Organizational Behavior (Fifteenth ). United States of America: Pearson Education, Inc.

Rothe, P., Lindholm, A.-L., Hyvonen, A., \& Nenonen, S. (2012). Work Environment Preferences - Does Age Make A Difference? Facilities, Vol. 30(Iss 1/2), pp. 78-95. https://doi.org/10.1108/02632771211194284

Sedarmayanti. (2011). Sumber Daya Manusia dan Produktivitas Kerja.

Senen, S. H., \& Solihat, S. (2008). Pengaruh
Motivasi Kerja Dan Kemampuan Kerja Karyawan Terhadap Produktivitas Kerja Karyawan Pada PT. Safilindo Permata. Jurnal Strategic, Vol. 7(September), pp. 115.

Siagian, S. P. (2013). Teori \& Praktek Kepemimpinan. Jakarta: Rineka Cipta.

Sugiyono. (2017). Metode Penelitian Kuantitatif, Kualitatif dan $R \& D$. Bandung: Alfabeta.

Usman, H. (2011). Manajemen Teori Praktek Dan Riset Pendidikan. Jakarta: Erlangga.

Valaei, N., \& Jiroudi, S. (2016). Job Satisfaction And Job Performance In The Media Industry: A Synergistic Application Of Partial Least Squares Path Modelling. Asia Pacific Journal of Marketing and Logistics, Vol. 28(Iss 5), pp. 984-1014. https://doi.org/10.1108/APJML10-2015-0160

Verhaest, D., \& Verhofstadt, E. (2016). Overeducation And Job Satisfaction: The Role Of Job Demands And Control. International Journal of Manpower, Vol. 37(Iss 3), pp. 456-473. https://doi.org/10.1108/IJM-04-2014-0106

Widyanata, R., \& Senen, S. H. (2016). Pengaruh Lingkungan Dan Kemampuan Kerja Terhadap Kinerja Karyawan PT. Ronadamar Sejahtera Cabang Bandung. Journal of Business Management Education, Vol. 1(No. 2), pp. 47-55.

(n.d.). Retrieved Agustus 4, 2018, from MIT Sloan Management Review: Https://sloanreview.mit.edu/ 